\title{
ANTIBACTERIAL AND SYNERGISTIC ACTIVITY OF TERMINALIA CHEBULA AND TERMINALIA BELLERICA FRUIT EXTRACTS AGAINST ESBL PRODUCERS
}

\author{
BHARANI THIRUNAVUKKARASU, NIRMALA PURUSHOTHAMAN*
}

Department of Microbiology, Mohamed Sathak College of Arts and Science, Chennai 600119, Tamilnadu, India

Email: nirmala_dineshkumar@yahoo.com

Received: 21 Aug 2017, Revised and Accepted: 13 Oct 2017

\begin{abstract}
Objective: Bacterial infections and the resistance related to indiscriminate antibiotic use have led to an alarming situation in the clinics. The rapid spread of Extended-Spectrum Beta-Lactamases (ESBLs) and carbapenemase producing Gram-negative bacteria has initiated the need for the development of a new drug or an alternative choice by using the combination of drugs with medicinal plant extracts. This study was aimed at examining the antibacterial potential and synergistic activity of ethanolic extracts of Terminalia chebula and Terminalia bellerica fruits against clinically important reference bacterial strains.
\end{abstract}

Methods: The crude ethanolic extracts of T. chebula and T. bellerica fruits were prepared and reconstituted with 5\% dimethylsulfoxide (DMSO). The fruit extracts $(\sim 25 \mathrm{mg} /$ well) were added into the wells in the plates inoculated with various ESBL and AmpC producers and they were incubated at $37^{\circ} \mathrm{C}$ for $24 \mathrm{~h}$. The antibiotics ceftazidime $(30 \mu \mathrm{g})$ and cefotaxime $(30 \mu \mathrm{g})$ were added to the wells alone and in combination with the fruit, extracts to determine their own antibacterial and synergistic activity respectively.

Results: The ethanolic fruit extracts combination improved the activity of ceftazidime and cefotaxime against the tested ESBL and AmpC producers. Though both the extracts showed activity, T. chebula was found to show better synergistic antibacterial activity.

Conclusion: The synergistic activity of these fruit extracts with ceftazidime and cefotaxime against the ESBL and AmpC producers shows the efficiency of the combination therapy, which can be considered in therapeutic point of view to prevent the misuse of antibiotics and minimise the increasing resistance in bacteria.

Keywords: ESBLs, Carbapenemase, Antibiotic, Synergy, Terminalia, Fruit extracts

(C) 2017 The Authors. Published by Innovare Academic Sciences Pvt Ltd. This is an open access article under the CC BY license (http://creativecommons.org/licenses/by/4.0/] DOI: http://dx.doi.org/10.22159/ijcpr.2017v9i6.23419

\section{INTRODUCTION}

Infectious diseases caused by bacteria affect millions of people worldwide. Treating bacterial infections with antibiotics is a good choice, but their indiscriminate use has led to an alarming rate of resistance among the bacterial population. Beta-lactamase mediated resistance in Gram-negative organisms poses a serious problem. Most of the ESBLs are serious threats to the usage of antibiotics in antibiotic therapy which results in loss of effective antibiotics and loss of budget for infectious disease treatment. Thus, there is an urgent and a constant need for exploration and development of cheaper, effective, new plant-based drugs with better bioactive potential and the fewest possible side effects. A few studies on the combination of antibiotics with various plant extracts have been reported [1-3]. The alternative is a combination therapy, which is beneficial for patients with serious infections caused by drug-resistant pathogens [4].

The synergistic effect of combining antibiotics with bioactive plant extracts against multi-drug resistant microorganisms can lead to new forms of treatment of infectious diseases. However, the selection of an appropriate combination requires an understanding of the potential for interaction between the antimicrobial agents. Synergistic therapy can be used to expand the antibacterial spectrum, to prevent the emergence of resistant mutants, to minimize toxicity and to obtain synergistic antibacterial activity [5]. Synergistic effects may be due to certain complex formations that become more effective in the inhibition of a particular species of microorganisms by inhibiting the cell wall synthesis, interfering with enzymes, or causing cell death. Sometimes the use of a single antibiotic does not produce the desired or effective inhibitory effects. To overcome this, a combination of drugs is often used, and their synergistic effect surpasses their individual performance.

Terminalia chebula and T. bellerica are members of the Combretaceae family. A medium-to large-sized tree distributed throughout tropical and sub-tropical Asia, including China and Tibet. In India, they are found in the forests of northern India, Uttar Pradesh, West Bengal, Tamil Nadu, Karnataka and southern Maharastra. The dried fruit of T. chebula commonly known as black myrobalan in English has traditionally been used as a popular folk medicine for an alternative, astringent, dentifrice, purgative, stomachic, tonic, antiseptic and laxative purposes. This fruit is also useful for burns, digestive disorders, diabetes, eye diseases, weak eyesight, fever, skin diseases and kidney dysfunction along with other herbs [6-8]. The observed health benefits may be credited to the presence of the various phytochemicals like polyphenols, terpenes, anthocyanins, flavonoids, alkaloids and glycosides. With the growing incidence of infections resistant to current antibiotics, an arsenal of new agents for supplementing current antibiotics is needed. The alternative is combination therapy, which is beneficial for patients with serious infections caused by drug-resistant pathogens [9].

The fruit of T. chebula is rich in tannins (about 32\%-34\%) and its content varies with the geographical distribution. The tannins of $T$. chebula is of pyrogallol (hydrolyzable) type. A group of researchers found 14 components of hydrolyzable tannins (gallic acid, chebulagic acid, punicalagin, chebulanin, corilagin, neochebulinic acid, ellagic acid, chebulinic acid, 1,2,3,4,6-penta-0-galloyl- $\beta$-D-glucose, 1,6-di-o-galloylD-glucose, casuarinin, 3,4,6-tri-o-glloyl-D-glucose, terchebulin) from $T$. chebula fruits [7]. Other constituents include phenolics such as chebulinic acid, ellagic acid and anthraquinones. Some of the other minor constituents were polyphenols such as corilagin, galloyl glucose, punicalagin, terflavin A, maslinic acid. Besides, fructose, amino acids, succinic acid, beta-sitosterol, resin and the purgative principle of anthraquinone are also present. Flavonol, glycosides, triterpenoids, coumarin conjugated with gallic acids called chebulin as well as other phenolic compounds were also isolated. Twelve fatty acids were isolated from T. chebula of which palmitic acid, linoleic acid and oleic 
acid were the main constituents [7]. Triterpenoid glycosides such as chebulosides I and II, arjunin, arjunglucoside, $2 \alpha$-hydroxyursolic acid and $2 \alpha$-hydroxymicromiric acid also have been reported. The leaves were found to contain polyphenols such as punicalin, punicalagin, terflavins B, C, and D. The plant is found to contain phloroglucimol and pyrogallol, along with phenolic acids such as ferulic, p-coumaric, caffeic and vanillic acids. Oil extracted from kernels yielded palmitic, stearic, oleic, linoleic, behenic and arachidic acids [7].

The inhibitory effect of fruit extracts of T. bellerica can be attributed to the chemical substances (gallic acid and ethyle gallate) that were present in the fruits. Chemical substances of $\beta$-sitosterol, gallic acid, ethyle gallate, galloyl glucose, a new triterpene, the belleric acid and chebulagic acid have been isolated from fruits of T. bellerica [10]. Tannins are also present in T. chebula fruits in the form of tannin-B. It has been recently reported that tannins and propyle gallate, were inhibitory to food-borne, waterborne and off-flavour producing microorganisms. The antimicrobial activity of propyle gallate was associated with the hydrolysis of an ester linkage between gallic acid and polyols that occurs when the fruits ripen. A similar mode of action can be predicted for ethylene gallate of $T$. bellerica fruits [11].

In view of the reported medicinal values of these fruit extracts, the present work was carried out to examine the antibacterial potential and synergistic activity of ethanol extracts of T. chebula and T. bellerica fruits against clinically important ESBL and AmpC producing CLSI (Clinical and Laboratory Standards Institute) and NCTC (National collection of type cultures) reference bacterial strains.

\section{MATERIALS AND METHODS}

\section{Collection, identifying and processing of fruit material}

The fruits of $T$. chebula and T. bellerica were collected from Ayurvedic/herbal market in Chennai, India, and identified by comparison with specimens available. The dried fruits were cleaned and homogenized to a fine powder and stored in airtight bottles.

\section{Extraction of plant material}

The crude extract was obtained by the addition of $100 \mathrm{~g}$ of dried fruit powder in $250 \mathrm{ml} 70 \%$ ethanol and kept on a rotary shaker at 120 RPM for $72 \mathrm{~h}$. The extract was filtered with Whatman No.1 filter paper, centrifuged at $3000 \mathrm{RPM}$ for $15 \mathrm{~min}$ and was dried in a rotary evaporator. The yield obtained was $20 \%$ with respect to the initial dry material. For experimental purposes, the extract reconstituted with $5 \%$ dimethylsulfoxide (DMSO) to a final concentration of $1 \mathrm{~g} / \mathrm{ml}$ and was stored in $4^{\circ} \mathrm{C}$ in airtight bottles.

\section{Bacterial strains}

The bacterial strains used in this study were kindly provided by Microbial Resource Orchid, Chennai, India. The strains include various ESBL producers such as K. pneumoniae ATCC 51503 (TEM10 and TEM12), Escherichia coli ATCC BAA 203 (SHV5), K. pneumoniae ATCC 700603 (SHV18), E. coli NCTC 13441 (CTX-M15), E. coli NCTC 13465 (CTX-M25), Enterobacter cloacae NCTC 1143 (Constitutive AmpC) and E. cloacae NCTC 13406 (De-repressed mutant of AmpC).

\section{Agar diffusion method}

Agar well diffusion method is widely used to evaluate the antimicrobial activity of plants or microbial extracts [12]. Similar to the procedure used in disk-diffusion method, the agar plate surface was inoculated by spreading $100 \mu \mathrm{l}$ of the microbial inoculum over the entire agar surface. Then, a hole with a diameter of 6 to $8 \mathrm{~mm}$ is punched aseptically with a sterile cork borer, and required volume of the antimicrobial agent or extract solution at desired concentration is introduced into the well. The fruit extracts were dissolved in DMSO to a final concentration of $1 \mathrm{~g} / \mathrm{ml}$. Thus, $25 \mu \mathrm{l}(\sim 25 \mathrm{mg} /$ well $)$ of the fruit extracts were added into the wells and the plates were incubated at $37{ }^{\circ} \mathrm{C}$ for $24 \mathrm{~h}$. The antibiotics ceftazidime $(30 \mu \mathrm{g})$ and cefotaxime $(30 \mu \mathrm{g})$ were added to the wells separately and in combination with the fruit, extracts to determine their own antibacterial activity and the synergistic activity with fruit extracts respectively. DMSO served as negative control and the tests were performed in triplicate. Antibacterial activity was evaluated by measuring the diameter of the inhibition zones around the well.

\section{RESULTS}

\section{Antibacterial and synergistic activity of $T$. chebula}

T. chebula showed moderate antibacterial activity against the tested ESBL producing strains with maximum activity against the SHV5 and de-repressed AmpC producing strains. Ceftazidime with T. chebula showed synergistic activity against TEM, SHV and AmpC producing strains while the activity was in-differentiate against CTX-M producers. The moderate activity of ceftazidime against the TEM, SHV and AmpC producers were found to improve with the addition of $T$. chebula indicating their synergistic activity [table 1a].

Cefotaxime alone showed good activity against most of the ESBL producers except CTX-M15 where it showed minimal activity while no activity against AmpC producers. T. chebula combination improved its activity by synergy against SHV18, CTX-M and AmpC producers, while the activity was in-differentiate against TEM and SHV5 producers [table $1 \mathrm{~b}]$.

\section{Antibacterial and synergistic activity of $T$. bellerica}

T. bellerica showed minimal antibacterial activity against the tested ESBL producing strains with maximum activity against the derepressed AmpC producing strain. Ceftazidime alone showed good activity against CTX-M producers while minimal activity against other ESBLs and AmpC producers. Ceftazidime with T. bellerica showed synergistic activity against TEM, SHV and constitutive and de-repressed AmpC producing strains and the activity was indifferentiate against CTX-M producers [table 2a].

Cefotaxime with $T$. bellerica showed synergistic activity against CTXM15 and AmpC producers while the activity was in-differentiate against other ESBL producers.

Thus the activity of both ceftazidime and cefotaxime were found to increase with the fruit extract of T. bellerica by synergy [Table 2b]. Though both the extracts showed selective synergistic activity with ceftazidime and cefotaxime against ESBL or AmpC producing bacterial strains, T. chebula was found to show better synergistic antibacterial activity.

Table 1a: Antibacterial and synergistic activity of $T$. chebula with ceftazidime against ESBL and AmpC producers

\begin{tabular}{|c|c|c|c|c|c|}
\hline \multirow[t]{2}{*}{ Strain } & \multirow[t]{2}{*}{ Genotype } & \multicolumn{3}{|c|}{ Zone of inhibition (mm) } & \multirow[t]{2}{*}{ Effect } \\
\hline & & T. chebula (25 mg) & Ceftazidime $(30 \mu \mathrm{g})$ & $\begin{array}{l}\text { T. chebula (25 mg)+Ceftazidime } \\
(30 \mu \mathrm{g})\end{array}$ & \\
\hline K. pneumoniae ATCC 51503 & TEM-10, TEM-12 & $10.67 \pm 0.58$ & $10.33 \pm 0.58$ & $23.17 \pm 0.58$ & $S$ \\
\hline E. coli ATCC BAA 203 & SHV -5 & $15.67 \pm 0.58$ & $17.00 \pm 0.00$ & $32.67 \pm 0.58$ & S \\
\hline $\begin{array}{l}\text { K. pneumoniae ATCC } \\
700603\end{array}$ & SHV-18 & $14.00 \pm 0.00$ & $15.17 \pm 0.29$ & $30.17 \pm 0.29$ & $S$ \\
\hline E. coli NCTC 13441 & CTX-M15 & $10.67 \pm 0.58$ & $23.0 \pm 0.00$ & $23.50 \pm 0.50$ & ID \\
\hline E. coli NCTC 13465 & CTX-M25 & $12.83 \pm 0.29$ & $27.50 \pm 0.50$ & $27.33 \pm 0.58$ & ID \\
\hline E. cloacae NCTC 1143 & Con. AmpC & $12.50 \pm 0.50$ & $10.67 \pm 0.58$ & $24.00 \pm 0.00$ & S \\
\hline E. cloacae NCTC 13406 & $\begin{array}{l}\text { Derepressed mutant } \\
\text { AmpC }\end{array}$ & $15.67 \pm 0.58$ & $11.33 \pm 0.58$ & $26.67 \pm 0.29$ & $S$ \\
\hline
\end{tabular}

ID-In-differentiate; S-Synergy 
Table 1b: Antibacterial and synergistic activity of $T$. chebula with cefotaxime against ESBL and AmpC producers

\begin{tabular}{|c|c|c|c|c|c|}
\hline \multirow[t]{2}{*}{ Strain } & \multirow[t]{2}{*}{ Genotype } & \multicolumn{3}{|c|}{ Zone of inhibition (mm) } & \multirow[t]{2}{*}{ Effect } \\
\hline & & T. chebula (25 mg) & Cefotaxime $(30 \mu \mathrm{g})$ & T. chebula (25 mg)+Cefotaxime (30 $\mu \mathrm{g})$ & \\
\hline $\begin{array}{l}\text { K. pneumoniae ATCC } \\
51503\end{array}$ & TEM-10, TEM-12 & $10.67 \pm 0.58$ & $24.67 \pm 0.29$ & $27.67 \pm 0.58$ & ID \\
\hline E. coli ATCC BAA 203 & SHV-5 & $15.67 \pm 0.58$ & $27.67 \pm 0.58$ & $28.33 \pm 0.58$ & ID \\
\hline $\begin{array}{l}\text { K. pneumoniae ATCC } \\
700603\end{array}$ & SHV-18 & $14.00 \pm 0.00$ & $18.00 \pm 0.00$ & $32.67 \pm 0.58$ & $\mathrm{~S}$ \\
\hline E. coli NCTC 13441 & CTX-M15 & $10.67 \pm 0.58$ & $12.00 \pm 0.00$ & $23.67 \pm 0.58$ & S \\
\hline E. coli NCTC 13465 & CTX-M25 & $12.83 \pm 0.29$ & $20.33 \pm 0.58$ & $33.17 \pm 0.29$ & S \\
\hline E. cloacae NCTC 1143 & Con. AmpC & $12.50 \pm 0.50$ & $0.00 \pm 0.00$ & $19.33 \pm 0.58$ & S \\
\hline E. cloacae NCTC 13406 & $\begin{array}{l}\text { Derepressed } \\
\text { mutant AmpC }\end{array}$ & $15.67 \pm 0.58$ & $0.00 \pm 0.01$ & $21.67 \pm 0.58$ & S \\
\hline
\end{tabular}

ID-In-differentiate; S-Synergy

Table 2a: Antibacterial and synergistic activity of $T$. bellerica with ceftazidime against ESBL and AmpC producers

\begin{tabular}{|c|c|c|c|c|c|}
\hline \multirow[t]{2}{*}{ Strain } & \multirow[t]{2}{*}{ Genotype } & \multicolumn{3}{|c|}{ Zone of inhibition (mm) } & \multirow[t]{2}{*}{ Effect } \\
\hline & & T. bellerica ( $25 \mathrm{mg}$ ) & Ceftazidime $(30 \mu \mathrm{g})$ & $\begin{array}{l}\text { T. bellerica } \\
(25 \mathrm{mg})+\text { ceftazidime }(30 \mu \mathrm{g})\end{array}$ & \\
\hline K. pneumoniae ATCC 51503 & TEM-10, TEM-12 & $10.3 \pm 0.58$ & $10.3 \pm 0.58$ & $23.0 \pm 0.00$ & $\mathrm{~S}$ \\
\hline E. coli ATCC BAA 203 & SHV-5 & $10.5 \pm 0.50$ & $17.3 \pm 0.58$ & $26.8 \pm 0.29$ & S \\
\hline $\begin{array}{l}\text { K. pneumoniae ATCC } \\
700603\end{array}$ & SHV-18 & $10.8 \pm 0.29$ & $15.2 \pm 0.29$ & $21.3 \pm 0.58$ & $\mathrm{~S}$ \\
\hline E. coli NCTC 13441 & CTX-M15 & $10.3 \pm 0.58$ & $22.8 \pm 0.29$ & $21.0 \pm 0.00$ & ID \\
\hline E. coli NCTC 13465 & CTX-M25 & $10.5 \pm 0.50$ & $27.8 \pm 0.29$ & $26.8 \pm 0.29$ & ID \\
\hline E. cloacae NCTC 1143 & Con. AmpC & $10.3 \pm 0.58$ & $10.3 \pm 0.58$ & $21.5 \pm 0.50$ & S \\
\hline E. cloacae NCTC 13406 & $\begin{array}{l}\text { Derepressed mutant } \\
\text { AmpC }\end{array}$ & $13.3 \pm 0.58$ & $12.5 \pm 0.50$ & $23.3 \pm 0.58$ & $\mathrm{~S}$ \\
\hline
\end{tabular}

ID-In-differentiate; S-Synergy

Table 2b: Antibacterial and synergistic activity of $T$. bellerica with cefotaxime against ESBL and AmpC producers

\begin{tabular}{|c|c|c|c|c|c|}
\hline \multirow[t]{2}{*}{ Strain } & \multirow[t]{2}{*}{ Genotype } & \multicolumn{3}{|c|}{ Zone of inhibition (mm) } & \multirow[t]{2}{*}{ Effect } \\
\hline & & $\begin{array}{l}\text { T. bellerica } \\
(25 \mathrm{mg})\end{array}$ & $\begin{array}{l}\text { Cefotaxime } \\
(30 \mu \mathrm{g})\end{array}$ & $\begin{array}{l}\text { T. bellerica ( } 25 \mathrm{mg})+ \text { Cefotaxime } \\
(30 \mu \mathrm{g})\end{array}$ & \\
\hline $\begin{array}{l}\text { K. pneumoniae ATCC } \\
51503\end{array}$ & TEM-10, TEM-12 & $10.3 \pm 0.58$ & $25.2 \pm 0.29$ & $24.0 \pm 0.50$ & ID \\
\hline E. coli ATCC BAA 203 & SHV-5 & $10.5 \pm 0.50$ & $27.0 \pm 0.00$ & $27.2 \pm 0.29$ & ID \\
\hline $\begin{array}{l}\text { K. pneumoniae ATCC } \\
700603\end{array}$ & SHV-18 & $10.8 \pm 0.29$ & $18.0 \pm 0.50$ & $24.3 \pm 0.58$ & ID \\
\hline E. coli NCTC 13441 & CTX-M15 & $10.3 \pm 0.58$ & $11.8 \pm 0.29$ & $23.2 \pm 0.29$ & $\mathrm{~S}$ \\
\hline E. coli NCTC 13465 & CTX-M25 & $10.5 \pm 0.50$ & $20.3 \pm 0.58$ & $21.5 \pm 0.50$ & ID \\
\hline E. cloacae NCTC 1143 & Con. AmpC & $10.3 \pm 0.58$ & $9.2 \pm 0.29$ & $24.2 \pm 0.29$ & $\mathrm{~S}$ \\
\hline E. cloacae NCTC 13406 & $\begin{array}{l}\text { Derepressed mutant } \\
\text { AmpC }\end{array}$ & $13.3 \pm 0.58$ & $9.0 \pm 0.00$ & $24.0 \pm 0.00$ & $S$ \\
\hline
\end{tabular}

ID-In-differentiate; S-Synergy

\section{DISCUSSION}

T. chebula and T. bellerica are important medicinal plants in Indian traditional medicine. Triphala is a traditional Ayurvedic herbal formulation consisting of the dried fruits of three medicinal plants (T. chebula, T. bellerica and Embilica officinalis also known as 'three myrobalans') used in the treatment of various clinical indications. The fruit extracts of T. chebula and T. bellerica were found to possess versatile medicinal properties and hence used in various Ayurvedic preparations to treat various ailments. The dried fruit pulp was extracted with $70 \%$ ethanol and the residue was recovered using a rotary evaporator. The extracts were tested against the common ESBL and AmpC producing bacteria and they showed a good antibacterial and also synergistic activity with ceftazidime and cefotaxime. In an earlier study a greater activity was exhibited on an alcoholic extract than the aqueous and hexane extracts against bacteria, with no cellular toxicity [13-14] and also a methanolic extract of T. bellerica showed the highest inhibition zones against $P$. aeruginosa and E. coli $[13,15]$. The two possibilities that may account for the higher antibacterial activity of alcoholic extracts are the nature of biologically active components (alkaloids, flavonoids, essential oil, terpenoids, tannins, etc.), which may get enhanced in the presence of ethanol; and the stronger extraction capacity of ethanol that may have yielded a greater number of active constituents responsible for antibacterial activity $[6,15]$. This study showed antibacterial activity at a low concentration, whereas an earlier study reported similar activity at a concentration of 200 $\mathrm{mg} / \mathrm{ml}$ [15]. It was also reported that a fruit ethanol extract of $T$. chebula exhibited antibacterial activity against S. aureus (MRSA) and the compounds responsible for this activity were gallic acid and its ethyl ester [16]. Activity against the clinical pathogen E. coli showed a MIC value of $6.25 \mathrm{mg} / \mathrm{ml}$ [17], which is almost similar to the present study. In a similar study with ethanolic fruit extracts of $T$. chebula nearly $40 \%$ growth inhibition was observed in $K$. pneumoniae at a concentration of $1 \mathrm{mg} / \mathrm{ml}[6,18]$.

\section{CONCLUSION}

In conclusion, both the $T$. chebula and T. bellerica fruit ethanol extracts showed a good spectrum of activity against ESBL and AmpC 
producing CLSI and NCTC reference bacterial strains and among them, T. chebula was found to be more effective which is similar to earlier observation [10]. These results support the beneficial effects of $T$. chebula and T. bellerica fruits for its antibacterial or antiseptic capacities $[6,10,19,20]$. However, further studies are warranted on the extract to explore the active antibacterial compounds and their activity on various ESBL and carbapenemase-producing bacteria and also against multi-drug resistant bacteria.

\section{ACKNOWLEDGMENT}

The authors would like to acknowledge Orchid Chemicals and Pharmaceuticals and Mohamed Sathak College of Arts and Science for supporting this project

\section{CONFLICT OF INTERESTS}

\section{Declared none}

\section{REFERENCES}

1. Rakholiya $\mathrm{K}$, Chanda $\mathrm{S}$. In vitro interaction of certain antimicrobial agents in combination with plant extracts against some pathogenic bacterial strains. Asian Pac J Trop Biomed 2012:S1416-S1470. Doi:10.1016/S2221-1691(12)60439-0

2. The wealth of India-A dictionary of Indian raw materials and industrial products. Vol. X. New Delhi: Publication and Information Directorate, CSIR; 2002. p. 522-4.

3. The wealth of India-A dictionary of Indian raw materials and industrial products. Vol. X. New Delhi: Publications and Information Directorate, CSIR; 2002. p. 387.

4. Chanda S, Rakholiya K. Combination therapy: Synergism between natural plant extracts and antibiotics against infectious diseases. In: Mendez-Vilas A. Ed. Science against Microbial Pathogens: Communicating Current Research and Technological Advances. Formatex Research Center; 2011. p. 520-9.

5. Pankey G, Ashcraft D, Patel N. In vitro synergy of daptomycin plus rifampin against Enterococcus faecium resistant to both linezolid and vancomycin. Antimicrob Agents Chemother 2005;49:5166-8.

6. Kannan P, Ramadevi SR, Waheeta Hopper. Antibacterial activity of Terminalia chebula fruit extract. Afr J Microbiol Res 2009;3:180-4

7. Anwesa Bag, Subir Kumar Bhattacharyya, Rabi Ranjan Chattopadhyay. The development of Terminalia chebula Retz. (Combretaceae) in clinical research. Asian Pac J Trop Biomed 2013;3:244-52.
8. Bag A, Bhattacharyya SK, Bharati P, Pal NK, Chattopadhyay RR. Evaluation of antibacterial properties of Chebulic myrobalan (fruit of Terminalia chebula Retz.) extracts against methicillinresistant Staphylococcus aureus and trimethoprimsulphamethoxazole resistant uropathogenic Escherichia coli. Afr J Plant Sci 2009;3:25-9.

9. Nisrat Jahan, Sharifa Jahan. Study on synergistic activity of ethanolic leave extract of Terminalia chebula in combination to Azithromycin and Ciprofloxacin against various bacterial strains. Eur J Med Plants 2016;13:1-11.

10. Elizabeth KM. Antimicrobial activity of Terminalia bellerica. Indian J Clin Biochem 2005;20:150-3.

11. Rastogi P, Mehrotra BN. Compendium of Indian medicinal plants, drug research perspective, CDRI, Lucknow and NISCOM, New Delhi 1999;2:1-859.

12. Mounyr Balouiri, Moulay Sadiki, Saad Koraichi Ibnsouda. Methods for in vitro evaluating antimicrobial activity: a review. J Pharm Anal 2016;6:71-9.

13. Ahmad I, Mehmood Z, Mohammad F. Screening of some Indian medicinal plants for their antimicrobial properties. J Ethnopharmacol 1998;62:183-93.

14. Phadke SA, Kulkarni SD. Screening of in vitro antibacterial activity of Terminalia chebula, Eclapta alba and Ocimum sanctum. Indian J Med Sci 1989;43:113-7.

15. Ghosh A, Das BK, Roy A, Mandal B, Chanda G. Antibacterial activity of some medicinal plant extracts. J Nat Med 2008;62:259-62.

16. Sato Y, Oketani H, Singyouchi K, Ohtsubo T, Kihara M, Shibata $\mathrm{H}$, et al. Extraction and purification of effective antimicrobial constituents of Terminalia chebula Retz. against methicillinresistant Staphylococcus aureus. Biol Pharm Bull 1997;4:401-4.

17. Chattopadhyay RR, Bhattacharyya SK, Medda C, Chanda S, Datta S, Pal NK. Antibacterial activity of black myrobalan (Fruit of Terminalia chebula Retz.) against uropathogenic Escherichia coli. Pharmacogn Rev 2007;11:212-5.

18. Suguna L, Singh S, Sivakumar P, Sampath P, Chandrakasan G. Influence of Terminalia chebula on dermal wound healing in rats. Phytother Res 2002;16:227-31.

19. Nithya Devi P, Kaleeswari S, Poonkothai M. Antimicrobial activity and Phytochemical analysis of fruit extracts of Terminalia bellerica. Int J Pharm Pharm Sci 2014;6:639-42.

20. Anindita Deb, Sikha Barua, Biswajit Das. Pharmacological activities of Baheda (Terminalia bellerica): a review. J Pharmacogn Phytochem 2016;5:194-7. 